ARTIGO

\title{
Meio ambiente e relações internacionais: perspectivas teóricas, respostas institucionais e novas dimensões de debate
}

ANA FLÁVIA BARROS-PLATIAU* MARCELO DIAS VARELLA** RAFAEL T. SCHLEICHER ${ }^{* * *}$

Rev. Bras. Polít. Int. 47 (2): I00- 130 [2004]

\section{Introdução}

Há só uma Terra, mas não só um Mundo. Todos nós dependemos de uma biosfera para conservar nossas vidas. Mesmo assim, cada comunidade, cada país luta pela sobrevivência e pela prosperidade quase sem levar em consideração o impacto que causa sobre os demais

Relatório Brundtland, Nosso Futuro Comum

A citação acima pertence a um dos mais impactantes relatórios já produzidos pelas Nações Unidas, o Relatório da Comissão presidida por Gro Harlem Brundtland, "Nosso Futuro Comum". Mesmo se a Terra fosse somente um pequeno espaço ou se houvesse apenas um rio,

* Professora do Instituto de Relações Internacionais da Universidade de Brasília (UnB).

** Pesquisador-associado do Centro de Desenvolvimento Sustentável da Universidade de Brasília e coordenador do curso de mestrado em Direito das Relaçôes Internacionais do Centro Universitário de Brasília (UNICEUB)

*** Mestrando em Relaçôes Internacionais na Universidade de Brasília e membro do Grupo de Estudos em Meio Ambiente (GERIMA). 
uma árvore, ou um animal, haveria infinitas formas de organizá-los e distribuí-los entre os homens, pois é evidente que a pintura do espaço humano depende do desejo de ver este ou aquele desenho sociopolítico. Entretanto, que colorações passariam a ter o espaço físico caso uma das formas de organização sociopolítica fosse preponderante sobre todas as outras e, progressivamente, esta forma de organização cedesse lugar a todas outras possibilidades? Em outras palavras, que opções e oportunidades emergem para a governança ambiental em um contexto de redefinição da soberania estatal e do próprio sistema internacional?

Comumente, as análises de política ambiental internacional e governança global ambiental trazem consigo uma distinção tripartite do meio ambiente em local/nacional/global, ${ }^{1}$ transfronteiriço/bens comunais globais/patrimônio comum da humanidade, ${ }^{2}$ ou ainda em natureza, demografia e tecnologia. ${ }^{3} \mathrm{~A}$ abordagem aqui utilizada é aquela proposta na citação comentada anteriormente entre Terra e Mundo, ou seja, entre o espaço "físico" e o "espaço humano". De fato, há de se alertar que apesar desta divisão ser extremamente útil para fins didáticos, a sua real operacionalização seria difícil, uma vez que o espaço "físico" pode ser socialmente construído, ou melhor, o que se chama aqui de Terra e meio ambiente depende fortemente de como os seres humanos os entendem. Contudo, o objetivo aqui deve ser pavimentar uma nova ontologia para o debate, não prover subsídio para o debate entre racionalistas e construtivistas.

Primeiramente, será necessária uma caracterização do que é o problema ambiental, para que se possa revelar posteriormente os três mecanismos pelos quais se entende o processo de gestão coletiva do meio ambiente. Em seguida, serão discutidas as opções e oportunidades institucionais no contexto de redefinição da soberania e surgimento de novos atores no sistema internacional. A quinta seção trará duas breves discussões acerca da adequação dos ideais de livre comércio e proteção

\footnotetext{
${ }^{1}$ PORTER, Gareth \& BROWN, Janet. Global environmental politics. Boulder: Westview, 1991, $208 \mathrm{p}$.

${ }^{2}$ ELLIOTT, Lorraine. The global politics of the environment. New York: New York University Press, 1998.

3 THEYS, Jacques. Les grands problèmes d'environnement: la vision dês scientifiques. Cahiers Français, Enjeux et politiques de l'environnement. Paris: La Documentation Française, 2002, 3-8 p.
} 
ambiental e sobre a necessidade de redefinição do papel da segurança no contexto da crise ambiental. A conclusão operacionalizará toda a discussão exposta e apontará opções e oportunidades de diálogo futuro entre as relações internacionais e o meio ambiente.

\section{Q que é o problema ou crise ambiental?}

Esta pergunta é extremamente relevante, porque é a partir de sua resposta que se pode construir uma ligação entre a área temática concebida como "meio ambiente" e as relações internacionais como campo do saber. A ligação entre ambas as áreas revela também uma perspectiva interessante relativa à necessidade de gestão coletiva da crise ambiental, uma vez que os problemas que constituem esta crise perpassam as tradicionais fronteiras territoriais dos Estados nacionais e demandam uma ação conjunta de todos os atores envolvidos. Como, então, pode ser entendida e definida a crise? Em adição, porque a gestão deve ser coletiva?

Em primeiro lugar, considere que a realidade que cerca a todos seja uma superposição de duas esferas. Uma denomina-se "Mundo", por cristalizar a gama de interações políticas, econômicas e sociais entre os indivíduos do globo. A outra será chamada de "Terra" pela capacidade de apreensão do conjunto das coisas físicas ou naturais. ${ }^{4}$ Portanto, a crise ambiental será aqui definida como a incongruência entre Terra e Mundo, ou seja, entre um espaço físico e outro socialmente construído. Todavia, se a crise é baseada na incongruência então, a sua solução, de forma geral, deveria estar baseada na convergência entre ambos.

O exame do pensamento ambiental ou ecológico revela três estilos de pensamento, implicando em diferentes caracterizações tanto para a

\footnotetext{
${ }^{4}$ Natureza é de fato um conceito impreciso. Esta palavra abrange essencialmente três significados: índole, marco inicial e conjunto de seres vivos. Sucintamente, natureza não determina uma relação, mas sim a definição da essência ou condição de grupo de um determinado organismo vivo. Quando se volta para a palavra meio ambiente, encontra-se também um problema, ainda que não semelhante ao da palavra anterior. Meio ambiente é comumente definido como "o que está em volta de algo" e "o que circunda o objeto sob análise". O conceito de meio ambiente aqui adotado será o exposto por Lynton Caldwell: "Uma relação entre o que ambienta e aquele que é ambientado". Ver: CALDWELL, Lynton K. International Environmental Policy: from the Twentieth to the Twenty-First Century. DurOham: Duke University Press, 1996, 13 p.
} 
crise ambiental, quanto para suas soluções. Tanto a Bíblia, ${ }^{5}$ quanto a economia clássica de Thomas Malthus são exemplos de um estilo de pensamento antropocêntrico que considera a "Terra como um conjunto de recursos à disposição da sociedade. Tomadas as constatações de Malthus, ${ }^{6}$ a crise ambiental poderia ser definida como recursos finitos para uma população exponencialmente crescente. As soluções seriam o próprio equilíbrio natural existente entre homem e "meio", a fome, ou controle populacional. Por outro lado, há abordagens geocêntricas, como a hipótese de Gaia elaborada por James Lovelock, ${ }^{7}$ ou melhor, a "Terra englobaria o "Mundo". Neste ponto, deve-se notar que os antípodas aqui definidos anteriormente, antropocentrismo e geocentrismo, são variantes de um discurso também presente na ecologia entre conservação ou preservação. ${ }^{8}$

O terceiro modelo seria aquele que conciliaria as abordagens antropocêntricas e geocêntricas. Especialmente após a tentativa de racionalização do problema ambiental em 1972, com a publicação do Relatório do Clube de Roma, intitulado The limits to growth, e a realização da Conferência das Nações Unidas sobre o Meio Ambiente Humano (UNCHE, em inglês), também em 1972, ficou claro que o problema ambiental gravitava em torno de duas temáticas centrais, o crescimento econômico ininterrupto e a exaustão dos recursos naturais. Também já havia sido demonstrado por vários economistas, como Ezra Mishan e Arthur Pigou, por exemplo, que o crescimento econômico, especialmente quando refletido pelo Produto Interno Bruto (PIB), não era capaz de contabilizar determinados custos oriundos do consumo e produção, as

\footnotetext{
5 "E disse Deus: façamos o homem a nossa imagem, conforme a nossa semelhança; e domine os peixes do mar, e sobre as aves dos céus, e sobre o gado, e sobre toda a Terra, e sobre todo réptil que se move sobre a Terra." (Gênesis, 26), ou ainda: "E Deus os abençoou, e Deus lhes disse: Frutificai e multiplicai-vos, e enchei toda a Terra, e sujeitai-a, e dominai sobre os peixes do mar, e sobre as aves dos céus, e sobre todos animal que se move sobre a Terra." (Gênesis, 28).

${ }^{6}$ Ver: An essay on the principle of population as it affects the future improvement of society, with remarks on the speculations of Mr. Godwin, Mr. Condorcet, and other writers.

${ }^{7}$ Além do livro de James Lovelock, A new look at life on Earth, há uma excelente revisão da teoria de Gaia em MIDGLEY, Mary. Individualism and the concept of Gaia. In: Review of International Studies, n. 26, p. 29-44. Massachusetts, 2000.

${ }^{8}$ Sucintamente, "conservar" significa manter a reprodutibilidade dos recursos com o objetivo de exploração para fins econômicos e "preservar" denota a intocabilidade de determinados recursos naturais.
} 
chamadas "externalidades negativas". 9 Além disto, o preservacionismo radical defendido por muitos ambientalistas, nas décadas de 1970 e 1980, não era solução, porque impunha restrições ao bem estar humano. ${ }^{10} \mathrm{O}$ que estava em jogo era a inexistência de uma abordagem que pudesse conciliar tanto a garantia de bem estar aos indivíduos, quanto a conservação e utilização racional dos recursos naturais. Tal abordagem surgiu nos anos 80, quando a International Union of Concerned Scientists (IUCS) lançou um documento chamado World Conservation Strategy: Living Resource Conservation for Sustainable Development, que trazia implicitamente uma sistematização da relação entre crescimento econômico insustentável e recursos naturais em exaustão, e o Relatório da Comissão Brundtland, Nosso Futuro Comum, reforçou e politizou o termo "desenvolvimento sustentável", ou seja, "O desenvolvimento que atende as necessidades do presente sem comprometer a habilidade das geraçôes futuras de atender suas próprias necessidades". ${ }^{11}$

Se a possível solução para a crise ambiental caminha pela idéia de convergência entre as esferas física e social, como e por que promover uma gestão coletiva? Muitos analistas das relações internacionais relembram o papel das fronteiras territoriais e dos Estados-Nação como possíveis forças beligerantes em um sistema internacional carente de autoridade central. Outros analistas ressaltam o porquê da necessidade de autoridade central para manutenção da ordem se o sistema internacional é constituído de inúmeras regras e normas tácitas ou informais que influenciam o comportamento dos Estados. Entretanto, é de menor importância para a crise ambiental a lente pela qual se entende as relaçôes internacionais porque tal crise pertence ao mundo físico e ultrapassa tanto fronteiras, quanto qualquer outro conceito assumido. $\mathrm{O}$ essencial para este campo do saber são os conflitos, arranjos institucionais - formais e informais - e negociações que emergem da gestão coletiva da crise ambiental. Ou seja, a crise é global no âmbito do problema da solução e da

\footnotetext{
${ }^{9}$ Ver: PIGOU, Arthur. The economics of welfare. 4 ed. Londres: MacMillan, 1948, 837 p, e MISHAN, Ezra. He costs of economic growth. Nova Iorque: Praeger, 1971, 190 p.

${ }^{10}$ LEIS, Hector Ricardo. A Modernidade Insustentável: As Criticas do Ambientalismo a Sociedade Contemporânea. Florianópolis: Editora da UFSC \& Editora Vozes, 1999, 261 p.

${ }^{11}$ CMMAD (Comissão Mundial de Meio Ambiente e Desenvolvimento). Nosso Futuro Comum. Rio de Janeiro: Editora Fundação Getúlio Vargas, 1988, 9 p.
} 
gestão. Três perspectivas emergem, então, da gestão coletiva da crise ambiental: governança global, regimes internacionais e as abordagens organizacionais.

\section{Perspectivas teóricas da gestão coletiva do meio ambiente}

“[...] nosso objetivo deve ser ajudar nossos estudantes, colegas, e o público mais amplo a entender a necessidade de governança em um mundo parcialmente globalizado e os princípios que fariam esta governança legítima."

Robert Keohane ${ }^{12}$

Abordagens organizacionais, regimes internacionais e governança global são as três abordagens mais comuns para analisar o problema da gestão coletiva do meio ambiente. Marie-Claude Smouts sugere que tais abordagens representam de fato o movimento da cooperação internacional desde a instituição do sistema internacional Vestfaliano no século XVII, rumo a uma possível governança mundial. ${ }^{13}$ Entretanto, tais conceitos exibem uma tendência relativamente comum nas ciências socais: a falta de refinamento teórico.

Entre as idéias de governança global e regimes internacionais há uma forte complementaridade. Kratochwil e Ruggie, em seu estudo sobre as organizações internacionais, fornecem um interessante ponto de partida: "O núcleo substantivo em torno do qual as várias abordagens teóricas se agregaram é o problema da governança internacional". ${ }^{14} \mathrm{Ou}$ seja, a governança global/internacional é o objeto de estudo do campo denominado "organizações internacionais". Mais claramente, o objeto de estudo deste campo seria verificar como pode existir governança na ausência de governo. Se ambos os conceitos pertencem a um mesmo subcampo de estudo, o que estabeleceria uma diferenciação entre eles?

12 KEOHANE, Robert. "Governance in a partially globalized world: presidential address, American Political Science Association, 2000.” In: American Political Science Review (APSR) 95, 1, March 2001, 11p.

${ }^{13}$ SMOUTS, Marie-Claude. "La coopération internationale: de la coexistence à la gouvernance mondiale”. In: SMOUTS, Marie-Claude (Ed.) Les nouvelles relations internationales: pratiques et théories. Paris: Sciences Po, 1998. p, 135-159.

${ }^{14}$ KRATOCHWIL, Friedrich \& RUGGIE, John G. "International Organization: a state of art on an art of the state”. In: International Organization 40, 4. Cambridge: MIT press 1986, 754 p. 
Uma sugestão de diferenciação, que inclui a proposta de Kratochwil e Ruggie, é fornecida por James Rosenau e Ernst-Otto Czempiel em Governança sem Governo, uma das obras mais conhecidas sobre o assunto. Para estes autores, o diferencial entre eles estaria no caráter de área temática dos regimes internacionais, conforme a definição de Krasner. ${ }^{15}$ Ou seja, o conceito de regimes internacionais seria menos abrangente que o de governança global, que seria o conjunto de todos os regimes internacionais, conclusão similar a de Olav Stokke: “[...] o conceito de governança implícito na análise de regimes é mais estreito do que aquele pretendido pela governança global". ${ }^{16} \mathrm{O}$ que seria, então, uma definição para governança global?

Governança é para Rosenau e Czempiel “[...] um sistema de ordenação que depende de sentidos intersubjetivos, mas também de constituições e estatutos formalmente instituídos”. Entretanto, se governança é um sistema de ordenação, e daí não é estranho que a definição acima seja semelhante àquela de "ordem mundial" proposta por Hedley Bull, ${ }^{17}$ então qual relação existe entre governança e ordem? Os próprios autores respondem: “[...] governança e ordem são fenômenos claramente interativos[...] a ordem é ao mesmo tempo uma precondição e uma conseqüência do governo. Uma coisa ajuda a explicar a outra, e nenhuma aparece em primeiro lugar". ${ }^{18}$ Se governança é um sistema de ordenação e não há hierarquia entre ordem e governança, seja esta última com ou sem governo, constituiu-se uma tautologia. A ordem é estabelecida por meio da governança, que por sua vez é um mecanismo de ordem. Isto é, ordem explicando a ordem.

A exemplo da idéia proposta por Rosenau e Czempiel pode-se perceber a dificuldade de precisão em relação tanto ao conceito de governança global, como também às outras duas abordagens que vêm

\footnotetext{
${ }^{15}$ ROSENAU, James \& CZEMPIEL, Ernst-Otto. Governança sem governo: ordem e transformação na politica mundial. Brasília: UnB, 2000, 21 p.

${ }^{16}$ STOKKE, Olav. "Regimes as governance systems". In: YOUNG, Oran (Ed.) Global governance: drawing insights from the environmental experience. Cambridge: MIT press, 1997, $30 \mathrm{p}$.

17 Por 'ordem mundial' entendemos os padrōes ou disposiçôes da atividade humana que sustentam os objetivos elementares ou primários da vida social na humanidade considerada em seu conjunto. Em: BULL, Hedley. A sociedade anárquica. Brasília: UnB, IPRI, 2002, p. 26.

${ }^{18}$ ROSENAU, James \& CZEMPIEL, Ernst-Otto. Governança sem governo: ordem e transformação na politica mundial. Brasília: UnB, 2000.
} 
sendo utilizadas com freqüência na área ambiental. Uma idéia que poderia apreender a relação entre os três conceitos é aquela que remete ao status jurídico da instituição e ao grau de inclusão dos atores na gestão coletiva do meio ambiente, de acordo com a figura abaixo. Em relação ao jurídico entende-se a existência de: (a) associação voluntária; (b) ato institutivo; (c) personalidade jurídica; (d) ordenamento jurídico interno; (e) existência de estrutura própria; (f) exercício de poderes próprios. ${ }^{19}$ Ou seja, o status jurídico remete ao grau de flexibilidade e formalidade de uma instituição social e a participação dos atores à legitimidade, cosmopolitanismo e democratização no processo de gestão coletiva. A seguir as três abordagens serão analisadas separadamente.

\section{Figura 1}

Relação entre governança global, regimes internacionais e abordagens organizacionais

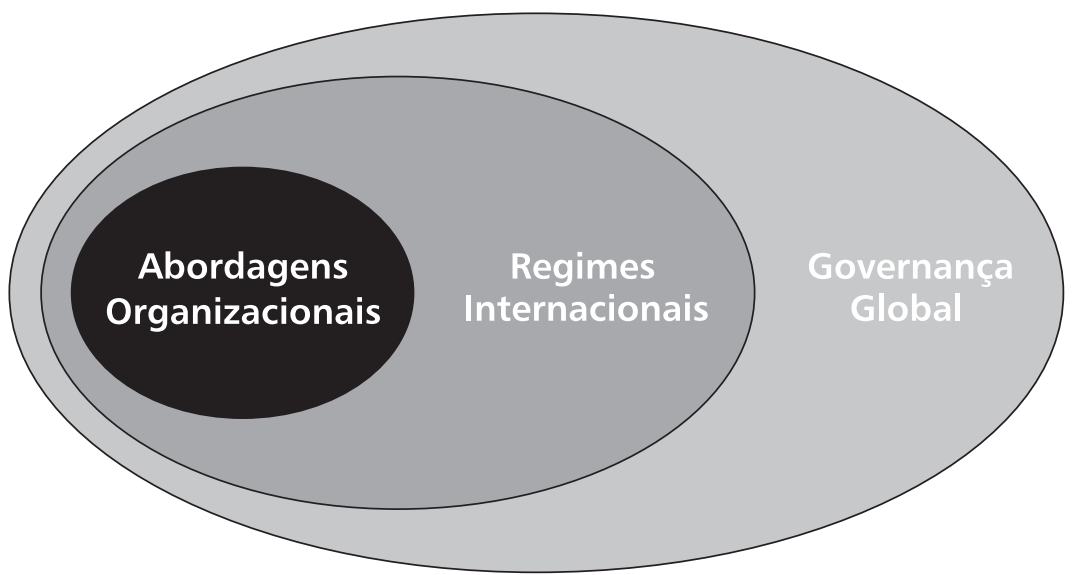

\section{Abordagens organizacionais}

O desenvolvimento destas abordagens surgiria a partir da discussão de "governo mundial" e da suposta necessidade de legalização das

\footnotetext{
${ }^{19}$ Ver: SOARES, Guido F. S. Direito internacional do meio ambiente: emergência, obrigaçôes e responsabilidades. São Paulo: Ed. Atlas, 2001; MELLO, Celso D. de Albuquerque. Curso de Direito Internacional Público. 14 ed. Rio de Janeiro: Renovar, 2002; REZEK, J. F. Direito Internacional Público: Curso Elementar. 8 ed. São Paulo: Ed. Saraiva, 2000.
} 
relações interestatais. Estas foram idéias que tiveram grande impacto nos estudiosos de Relações Internacionais, segundo Inis Claude Jr., escrevendo em 1962, não devido à operacionalização de tal governo, mas sim à idéia de "ordem mundial" que vinha incrustada em tal discussão. ${ }^{20}$ De fato, as primeiras abordagens para o estudo das Organizaçóes Internacionais (OI's) também exibiriam a proposição que o mundo poderia caminhar para a centralização de poder, para uma organização ou governo mundial.

Katzenstein et alii propõe a partir da análise do periódico mais consagrado no estudo das Organizações Internacionais, que em suas duas primeiras décadas de publicação, 1947-1967, a revista International Organization teve temas centrais que gravitaram em torno da análise de organizações formais, em especial as Nações Unidas (ONU). ${ }^{21}$ A categorização de Katzenstein et alii é similar às três categorias iniciais do estudo das Organizaçōes Internacionais (OI's) para Kratochwil e Ruggie. A primeira, o estudo das instituições formais, buscaria o que as OI's são, considerando-se que a governança internacional seria qualquer coisa que estas organizações façam. A seguir, o estudo dos processos institucionais das OI's buscava desvendar como estas se constituem e funcionam, com atenção especial à ONU. Finalmente, a categoria "papel organizacional" é exatamente aquela que cujos enfoques constariam a gestão de bens comuns e, novamente, a tradição de "governo mundial" na roupagem dos estudos funcionalistas e neofuncionalistas.

O ano de 1967 marcaria a aprovação da resolução anti-sionismo na Assembléia Geral das Nações Unidas, fato que teria provocado o desinteresse norte-americano na organização. Além disto, a détente américo-soviética, o processo de descolonização afro-asiática, junto a emergência do Terceiro Mundo como uma força contestadora da Ordem Econômica Mundial, as modificaçôes estruturais trazidas com a Terceira Revolução Industrial - fazendo emergir centros de poder alternativos no sistema internacional, como Alemanha e Japão - e as crises energéticas

\footnotetext{
${ }^{20}$ CLAUDE, Inis. Power and international relations. New York: Random House, 1962, p. 209-210.

${ }^{21}$ KATZENSTEIN, Peter; KEOHANE, Robert \& KRASNER, Stephen. International Organization and the study of world politics. In: International Organization 52, 4. 659-660 p. Cambridge: MIT press, 1998.
} 
trouxeram profundas modificações às abordagens organizacionais durante o período 1967-1969. ${ }^{22}$ Desta forma, Suhr coloca que:

Em reação ao papel exagerado das Organizações Internacionais nos estudos em Relações Internacionais John Gerard Ruggie introduziria o conceito de regimes. Ele proclamava uma mudança de foco para como a resposta coletiva deveria ser analisada como padrões mais amplos e informais de comportamento estatal. Portanto, ele buscou conceituar o espaço em que as Organizaçōes Internacionais operam. ${ }^{23}$

Ou seja, o declínio da hegemonia norte-americana aliado a um novo milieu internacional impulsionou uma nova geração de abordagens e análises, dentre as quais a de Regimes Internacionais, examinada na próxima seção.

Entretanto, o fim da bipolaridade trouxe conseqüências mais profundas para estas abordagens. Se por um lado houve uma tendência de fragmentação entre povos e dentro dos territórios nacionais, por outro houve também coesão e integração, como demonstra o caso da criação da União Européia. ${ }^{24}$ De qualquer forma, foi evidente que modificações profundas na ordem internacional Vestfaliana estavam em curso, devido ao surgimento e consolidação de novas identidades coletivas. As organizaçōes internacionais, com atenção especial à ONU, falharam na gestão destes novos problemas e questões globais, ${ }^{25}$ fossem eles de segurança, como as sucessivas crises nas operaçóes e de manutenção da paz, em meio ambiente, vide os problemas de executabilidade (enforcement) dos principais instrumentos oriundos da Conferência do Rio (1992) ou dos péssimos balanços da Conferência de Joanesburgo (2002), ou na área de desenvolvimento, como ficou evidente quando da publicação dos frustrantes resultados finais da "Década do Desenvolvimento da ONU”. Todos estes fatores contribuíram para a caracterização da

\footnotetext{
22 SARAIVA, Flávio (Org.). Relaçôes Internacionais - Dois séculos de história. Volume II. Brasília: Instituto Brasileiro de Relações Internacionais (IBRI); Funag, 2001.

${ }^{23}$ SUHR, Michael. "Robert Keohane: A contemporary classic”. In: NEUMANN, Iver \& WÆVER, Ole. The future of international relations. London; New York: Routledge, 1997, 95-96 p.

${ }^{24}$ Sobre o assunto ver: LESSA, Antônio. A construção da Europa: A última utopia das Relações Internacionais. Brasília: Instituto Brasileiro de Relações Internacionais (IBRI); Funag, 2003, 191p. ${ }^{25}$ MURPHY, Craig. Global governance: poorly done and poorly understood. In: International Affairs 76, 4. 2000, 790-792 p.
} 
tão difundida "Crise do Multilateralismo" e para que se buscassem abordagens mais flexíveis e novos conceitos operacionais.

\section{Regimes internacionais}

Com a definição do "paradigma" neo-realista por Kenneth Waltz, no início da década de $1970,{ }^{26}$ os estudiosos do campo das Relações Internacionais começaram a questionar que apesar do sistema internacional carecer de autoridade central, os Estados pareciam estar imiscuídos em uma rede institucional em um sentido mais amplo, em regras implícitas e explícitas que contribuíam para a modificação do comportamento estatal e eventualmente para a convergência com o comportamento dos demais. Em outras palavras, "A análise de regimes tentou preencher esta lacuna pela definição de um foco que não era tão amplo quanto o sistema internacional, ou tão estreito quanto o estudo das organizações internacionais". ${ }^{27}$ Martin Griffiths sugere uma razão semelhante para o surgimento da Teoria de Regimes Internacionais. Segundo este autor, as abordagens "realistas" das relações internacionais, com especial ênfase na famosa "Teoria de Estabilidade Hegemônica", desenvolvida separadamente por Stephen $\operatorname{Krasner}^{28}$ e Robert Gilpin, ${ }^{29}$ não eram capazes de explicar certos acontecimentos da vida internacional. Assim, estudiosos de inclinação liberal, como Robert Keohane, “[...] foram responsáveis pela popularização da idéia de regimes como variáveis que interferiam no poder do Estado, de um lado, e nos resultados internacionais, do outro". ${ }^{30}$

Seria exatamente como uma variável interveniente que os Regimes Internacionais iriam ser definidos por Stephen Krasner, ou melhor,

\footnotetext{
${ }^{26}$ WALTZ, Kenneth. Theory of international politics. 2 ed. New York: Mcgraw-Hill, 1979. 271 p. ${ }^{27}$ HAGGARD, Stephan \& SIMMONS, Beth. Theories of international regimes. In: International Organization 41, 3. 492 p. Cambridge: MIT press. Summer; 1987.

${ }^{28}$ Ver: KRASNER, Stephen. State Power and the structure of international trade. In: World Politics 28, 1976, 317-346 p.

${ }^{29}$ Ver: GILPIN, Robert. War and change in world politics. Cambridge: Cambridge University Press, 1981 \& GILPIN, Robert. Economia política das relações internacionais. Brasília: EdUnB, 2002.

${ }^{30}$ GRIFFITHS, Martin. 50 grandes estrategistas das Relaçôes Internacionais. São Paulo: Contexto, 2004, 57-8 p.
} 
"Regimes internacionais são definidos como princípios, normas, regras e procedimentos de tomada de decisão, sobre os quais as expectativas dos atores convergem em uma determinada área temática". ${ }^{31}$ Todavia, nem todos atores, entre eles alguns que contribuíram para o próprio volume editado por Krasner, concordam com essa definição e de fato, como Smouts et alii ressalta, a formulação da Teoria de Regimes foi abalada pelo "modismo intelectual" e, naturalmente, pela imprecisão conceitual. ${ }^{32}$ Stephan Haggard e Beth Simmons propõem uma divisão em quatro correntes para a Teoria de Regimes Internacionais: estrutural, estratégica ou teoria dos jogos, funcional e cognitiva. ${ }^{33}$ Pode-se adotar ainda a divisão mais sucinta, embora similar, proposta por Hasenclaver et alii entre neoliberais, realistas e cognitivistas. ${ }^{34}$

De forma simples, a abordagem neoliberal tem tal nome porque se baseia fortemente na teoria microeconômica e é funcional porque o Regime Internacional surgiria para cumprir a tarefa de reduzir as incertezas entre os atores e fazê-los caminhar para resultados "ótimos". Neste grupo se encaixariam tanto as abordagens de "Teoria dos Jogos" quanto a funcional, cujo melhor exemplo é a obra After Hegemony, de Robert Keohane. Já nas abordagens estruturais, ou realistas, o poder é a variável central, uma vez que a sua distribuição entre os atores do sistema internacional influencia fortemente na possibilidade de formação

${ }^{31}$ KRASNER, Stephen. "Structural causes and regime consequences: regimes as intervening variables”. In: KRASNER, Stephen (Ed.). International regimes. 8 ed. Ithaca: Cornell University Press, 1995, 1 p. Ainda que a definição mais utilizada para Regimes Internacionais encontre-se nesta obra citada é importante levar em consideração que o conceito surgiu pela primeira vez em um artigo de John Gerard Ruggie sobre as respostas institucionais para a tecnologia, artigo que também trouxe a idéia de "comunidades epistêmicas", outro conceito que viria a ser refinado por Peter Haas, em 1992, nas páginas do periódico International Organization. Cambridge: MIT press. Ver: RUGGIE, John G. International responses to technology: concepts and trends. In: International Organization 29, 3, Summer 1975; HAAS, Peter. Introduction: epistemic communities and international policy coordination. In: International Organization v. 46, n. 1. Cambridge: MIT press. Winter 1992.

32 SMOUTS, Marie-Claude et alii. Dictionnaire des relations internationales. Paris: Dalloz, 2003, $231 \mathrm{p}$.

${ }^{33}$ Idem 17.

${ }^{34}$ HASENCLAVER, A. Et alii. Integrating theories of international regimes. In Review of International Studies (2000), 26, 3-33. Ou ainda: HASENCLEVER, Andreas; MAYER, Peter \& RITTBERGER, Volker. Theories of international regimes. Cambridge: Cambridge University Press, 2001, 248 p. 
e declínio dos regimes internacionais, como lembram Krasner e Gilpin com a "Teoria da Estabilidade Hegemônica" ${ }^{35}$ Por fim, as abordagens rotuladas como "cognitivistas" têm fortes raízes na filosofia da ciência, como uma crítica ao racionalismo, e na sociologia, enfatizando questôes de aprendizado, percepçóes e identidades de grupo. Um exemplo desta última abordagem é encontrado nas precisas críticas de Kratochwil e Ruggie à definição de Regimes Internacionais proposta por Krasner. ${ }^{36}$ As escolas de pensamento para a Teoria de Regimes Internacionais estão sistematizadas na tabela 1 .

\section{Tabela 1}

\section{Escolas de pensamento no estudo de regimes Internacionais}

\begin{tabular}{l|l|l|l}
\hline & Realismo & Neoliberalismo & Cognitivismo \\
\hline Variável Central & Poder & Interesse & Conhecimento \\
\hline Orientação Metateórica37 & Racionalista & Racionalista & Sociológica \\
\hline Modelo & Ganhos relativos & Utilitarista & Interpretativo \\
\hline Comportamental & & Ganhos absolutos & \\
\hline \hline
\end{tabular}

Fonte: HASENCLAVER, A. et alii. "Integrating theories of international regimes". In Review of International Studies (2000), 26, 11 p. (Com adaptações).

${ }^{35}$ Idem 18 e 19.

36 Para estes autores, a teoria de regimes internacionais, essencialmente a definição proposta por Krasner, padece de vários males. O primeiro é que há uma confusão entre ontologia e epistemologia uma vez que o comportamento é derivado de uma construção conceitual (regimes) dada, não socialmente construída. Ou seja, "[...] regimes become external constraints on actors, not intersubjective frameworks". Se os regimes são conhecidos, ontologia, pelos entendimentos compartilhados e desejados de determinado comportamento social e o método positivista que é utilizado na construção do conceito não consegue captar este caráter, definido por Kratochwil e Ruggie como intersubjetivo, então o que se sabe contradiz aquilo que se analisa, em outras palavras, a epistemologia (aquilo que se sabe) contradiz a ontologia (realidade ou aquilo que se definiu como sendo ela). Além disto, a hierarquia entre normas, regras, princípios e procedimentos de tomada de decisão não fazem sentido, segundo estes autores, porque tanto os meios (normas e princípios) quanto os fins (regras e procedimentos) são mutuamente constitutivas do resultado final (regimes internacionais). Em outras palavras: "Actors not only reproduce normative structures, they also change them by their very practice, as new constraints or possibilities emerge, or new claimants make their presence felt". Ver: KRATOCHWIL, Friedrich \& RUGGIE, John G. International Organization: a state of art on an art of the state. In: International Organization 40, 4. Cambridge: MIT press. Autumn 1986.

37 Sobre metateoria e debates meteóricos nas Relações Internacionais ver: ROCHA, Antônio J. R. Relaçôes internacionais: teorias e agendas. Brasília: Instituto Brasileiro de Relaçōes Internacionais (IBRI), Funag: 2002; HOLLIS, Martin \& SMITH, Steve. Explaining and understanding international relations. Oxford: Claredon, 1991, $226 \mathrm{p}$. 


\section{Governança global}

$\mathrm{Na}$ citação que introduz a seção sobre perspectivas teóricas, Robert Keohane salienta o caráter parcialmente globalizado do mundo e a necessidade de governança efetiva. Por conseguinte, um enorme rol de questōes emerge. Entre elas, o que é governança? Ela é realmente global? A governança é efetiva ou é apenas um ideal liberal?

De fato, a segunda pergunta já foi respondida pelo próprio Keohane. A governança não é global, porque o mundo é parcialmente globalizado. Neste ponto é necessária uma distinção entre globalismo e globalização, tal qual proposta por Ulrich Beck. Globalismo pressupõe o estado pleno de globalização econômica, quando a expansão dos mercados em seu grau máximo substitui a política. Por outro lado, a globalização

[...] significa os processos, em cujo andamento os Estados nacionais vêem a sua soberania, sua identidade, suas redes de comunicação, suas chances de poder e suas orientaçōes sofrerem a interferência cruzada de atores transnacionais ${ }^{38}$ ou [...] o aprofundamento da distância em escala mundial através da emergência e estreitamento das redes de conexões - ambientais e sociais, assim como econômicas. ${ }^{39}$

Assim, qualquer análise que leve em consideração a idéia de governança global trará um forte grau de normatividade.

Em relação à definição de governança global há duas questões em ordem. A primeira é relativa à idéia de governança global proposta pelo professor Craig Murphy, onde esta seria a expansão do projeto liberal em escala global. ${ }^{40}$ Como Beck relembra, esta discussão é de fato sobre globalismo e não globalização, que pressupõe a idéia de governança global. Em segundo, há de se distinguir entre as possíveis idéias de definição para governança. Marie-Claude Smouts et alii propõe uma estrutura

\footnotetext{
38 BECK, Ulrich. O que é Globalização? Equívocos do Globalismo e respostas a Globalização. São Paulo: Paz e Terra, 1999, 27-30 p.

39 KEOHANE, Robert. Governance in a partially globalized world: presidential address, American Political Science Association, 2000. In: American Political Science Review (APSR) v.1, n.95, March, 2001, p. 1.

${ }^{40}$ MURPHY, Craig. Global governance: poorly done and poorly understood. In: International Affairs v.4, n.76, 2000, p. 789-803.
} 
tripartite entre "Governança Corporativa", um critério de boa governabilidade formulado pelo Banco Mundial (Bird) no fim dos anos 80, "Governança Multinível”, que diz respeito ao estilo de tomada de decisão na União Européia, e finalmente a "Governança sem Governo", conceito cunhado por Rosenau e Czempiel, que traz a idéia de que o mundo caminharia rumo a uma poliarquia, no sentido proposto por Robert Dahl, relacionando o caráter transnacional-estatal da política mundial e a idéia de globalização. ${ }^{41}$ Por fim, há a abordagem de Robert Keohane, que entende a "Governança como um Dilema” sobre como desenhar instituições para desempenhar funções desejadas e ao mesmo tempo respeitar os valores democráticos em um mundo parcialmente globalizado.

De fato, qualquer idéia de governança sempre irá pressupor um alto grau de capacitação dos indivíduos que estão sendo governados. Ou seja, qualquer definição de governança passará pela idéia de democratização e legitimidade ou de comunicação aberta e reflexividade coletiva. Mesmo que não haja uma definição ideal para governança, uma vez que esta própria palavra pode ser considerada um ideal, a proposta de agenda positiva de Robert Keohane é um ótimo ponto de partida para uma definição de governança: analisar o papel do processo de institucionalização na expansão dos ideais democráticos e no fortalecimento das capacidades dos indivíduos em nível global. Esta proposta é convergente com aquela de "Novo Multilateralimo", elaborada pelo professor canadense Robert Cox, que pressupõe uma ordem mundial construída "de baixo para cima" com objetivo de justiça, equidade e respeito ao outro, como bem sintetiza a professora Marie-Claude Smouts. ${ }^{42}$

\section{Respostas institucionais}

As respostas institucionais são aqui entendidas não em função das teorias de relações internacionais, mas em razão das iniciativas multilaterais já estabelecidas ou em vias de debate. Elas foram divididas

\footnotetext{
${ }^{41}$ SMOUTS, Marie-Claude et alii. Dictionnaire des relations internationales. Paris: Dalloz, 2003, 237-240 p.

42 SMOUTS, Marie-Claude. La coopération internationale: de la coexistence à la gouvernance mondiale. In: SMOUTS, Marie-Claude (Ed.) Les nouvelles relations internationales: pratiques et théories. Paris: Sciences Po, 1998, 154 p.
} 
em quatro grandes temas: o Programa das Nações Unidas para o Meio Ambiente (Pnuma); a Comissão de Desenvolvimento Sustentável (CDS) e a Organização das Nações Unidas para o Meio Ambiente (Onuma); as respostas regionais e as iniciativas das Organizações da Sociedade Civil (OCS). Todas elas foram criadas para trazer respostas às crises ambientais passadas (como a poluição e a maré negra) ou anunciadas, com vistas ao estabelecimento de mecanismos de governança ambiental. Ademais, ressalte-se que as últimas, principalmente as ONGs e as comunidades científicas ${ }^{43}$ foram estabelecidas principalmente pela falta de capacidade do Estado de agir no quadro analítico do interesse nacional e soberano, atestando a necessidade de novos arranjos institucionais mais flexíveis, que englobariam atores internacionais emergentes. ${ }^{44}$

O Pnuma foi criado após a Conferência de Estocolmo, ${ }^{45}$ mas revelou a crise política entre Estados favoráveis à criação de uma verdadeira organização do sistema ONU e aqueles opostos. Apesar de ter sido freqüentemente simplificada pela clivagem Norte/Sul, tal controvérsia já demonstrava sinais de interesses econômicos capazes de polarizar subgrupos nos dois campos. De fato, o debate político havia sido colocado em termos equivocados, como se o desenvolvimento dos países do Sul constituísse a grande ameaça ao meio ambiente, e os líderes do Norte tivessem que fazê-los observar as normas ambientais tidas como necessárias. Com o fracasso da iniciativa de criação da Onuma, criou-se apenas um programa, com sede

\footnotetext{
${ }^{43} \mathrm{O}$ conceito de comunidades epistêmicas de Peter Haas poderia ter sido usado aqui, mas preferiram as comunidades científicas porque várias delas acabam exercendo influência no processo decisório e legislativo independentemente de um objetivo inicial de fazê-lo. Além disso, é difícil de estabelecer se têm valores comuns, e a intersubjetividade que o autor definiu, como no caso da Iucs. Finalmente, o próprio autor está testando o seu conceito, com a pergunta se a comunidade de operadores e professores do direito internacional público se considera parte de uma suposta "comunidade epistêmica". Para uma crítica européia do conceito, ver Marc PALLEMAERTS, Toxics and Transnational Law, Oxford: Hart, 2003.

${ }^{44}$ CHURCHILL, R.; UFSTEIN, G. Autonomous Institutional Arrangements in Multilateral Environmental Agreements/ a Little Noticed Phenomenon in International Law. The American Journal of International Law, vol.94, 623-659 p. 2000. Washington. FISHER, D.; GREEN, J. Understanding Disenfranchisment: Civil Society and Developing Countries; Influence and Participation in Global Governance Influence for Sustainable Development. Global environmental Politics, 4, 3, p. 65-84. Cambridge: MIT press. August 2004.

${ }^{45}$ Nos termos de "urgent need for a permanent institutional arrangement within the United Nations system for the protection and improvement of the environment". Resolução no 2.997 da Asembléia Geral da ONU de 1972.
} 
em Nairóbi. ${ }^{46}$ Os países nórdicos e os membros da atual União Européia eram favoráveis a uma iniciativa institucional, mas o resto do mundo via com desconfiança a criação de uma instituição com objetivos ambientais construídos a partir da percepção do Norte.

Pelo fato do seu nascimento indesejado, mas principalmente por uma grande inversão de tendências nas décadas seguintes, o Pnuma nunca teve o papel importante no cenário internacional. ${ }^{47}$ Primeiro, passaram-se muitos anos até que sua existência fosse reconhecida de fato. Segundo, alguns países do Sul, principalmente africanos, começaram a usar o Pnuma como fórum de debate deles, e a inversão foi que o Sul se pôs a militar por um papel de desenvolvimento para o Pnuma, em sintonia com o contexto internacional da época, isto é, na exigência por uma nova ordem econômica internacional pouco antes da chamada "década perdida". Aos poucos, o Pnuma foi "colonizado" pelos países do Sul, e foi literalmente "esvaziado" pelos países financiadores, como também ocorreu com outras OI's, como a Unctac, Unido e Unesco. Além disso, a questão ambiental foi adotada por várias outras OI's, com mandatos diferentes e, às vezes, até programas concorrentes. ${ }^{48}$

No final da década de 1990, e com os resultados decepcionantes do pós-Rio 1992, o debate sobre a necessária criação da Onuma foi retomado, por uma iniciativa franco-alemã. $\mathrm{Na}$ verdade, a proposta é intimamente ligada à OMC. Primeiro, foi apresentada como uma resposta institucional à poderosa Organização Mundial de Comércio, para que as questões ambientais não fossem tratadas como uma mercadoria. Segundo, tentou-se aproveitar a analogia da transformação do Gatt em algo forte e institucionalizado, e fazer o mesmo com a regulação ambiental.

\footnotetext{
${ }^{46}$ A localização da sede na África foi fruto da reivindicação dos países do Sul, intencionado manter controle sobre as atividades do programa. Ver Le Preste, P. A Ecopolítica Internacional, São Paulo: SENAC, 2001.

${ }^{47}$ DESAI, B. Mapping the Future of International Environmental Governance. Ulfstein Yearbook of International Environmental Law, vol. 13, 2003. Paper prepared for the Global Environmental Governance: the Post-Johannesburg Agenda, 23-25 October 2003, Yale Center for Environmental Law and Policy, New Haven. Disponível em: www.yale.edu/gegdialogue/papers.htm. Também von MOLTKE, K. The Organization of the Impossible. Global Environmental Politics . v.1 n.1, p. 23 -8. Cambridge: MIT press, 2001.

48 TOEPFER , K. UN Task Force on Environment and Human Settlements, Report to the Secretary-General, 15 June, 1998.
} 
Terceiro, e mais sutil, foi a tentativa de esvaziar definitivamente a agenda da $\mathrm{OMC}$ relativa à questão agrícola e ambiental, que constitui o maior ponto de discórdia entre a União Européia e países com grande importância ambiental, como o Brasil e a Índia. Além disso, há um paralelo incontornável da convergência de regimes internacionais de proteção da pessoa humana e proteção ambiental, que tornaram o contexto favorável a uma nova iniciativa do Norte.

Entretanto, a iniciativa, que foi debatida juntamente à questão do "moribundo Pnuma, em Joanesburgo, 2002, na ocasião da Cúpula Mundial sobre Desenvolvimento Sustentável, não obteve o apoio dos países do Sul, e muito menos do Brasil. Dentre as diversas razões, entre elas algumas já expostas anteriormente, está o fato que o Brasil demanda que as organizações já criadas se tornem realmente operacionais, no sentido de que os membros cumpram os compromissos assumidos, em especial no que concerne à transferência de tecnologia e à cooperação internacional. Por isso, o Brasil defendeu a posição de fortalecimento da Comissão sobre Desenvolvimento Sustentável (CDS) no lugar da criação de mais uma OI fraca e irrealisticamente ambiciosa, que seria a Onuma. O Sul em geral, e para os brasileiros em particular, o que interessa é a promoção do desenvolvimento para a garantia da proteção ambiental de maneira sustentada, e não apenas a criação de mecanismos pretendendo contrabalançar o poder da $\mathrm{OMC}$ e menos ainda de mecanismos repressivos e orientados, como um suposto Tribunal Penal Internacional Ambiental. ${ }^{49}$ Em suma, existe uma grande crise do multilateralismo contemporâneo, pois as OI's criadas não reagiram às mudanças internacionais recentes, como o multilateralismo à la carte de George W. Bush e a sua política externa unilateral/bilateral, e a preponderância da política econômica acima de todos os outras, mesmo quando o tema é normativo demais, como no caso da política ambiental.

Uma das melhores soluçôes apontadas em fóruns internacionais ${ }^{50}$ tem sido a abordagem regional, ou em blocos, para evitar os entraves e impedimentos encontrados na cooperação internacional para a

\footnotetext{
${ }^{49}$ Apesar de a proposta do TPIA não ter sido formulada junto com a Onuma, uma grande parte dos militantes pela Onuma defende um futuro tribunal específico, principalmente os membros da sociedade civil organizada na Europa.

${ }^{50}$ Yale (2003), Paris (2004) e Viena (2004) para citar apenas três.
} 
governança ambiental. Esta idéia faz sentido, uma vez que a dinâmica regional tem sido privilegiada em outros campos da política, com um sucesso relativamente muito maior do que em outros níveis de análise. No caso da União Européia, a regulação ambiental tem evoluído consideravelmente, com a doutrina, servindo de inspiração para as outras partes do mundo. Para o "continente" norte-americano, a questão ambiental é tratada claramente em segundo plano, ou ao menos, tem o mérito de se evitar discursos retóricos para encobrir políticas econômicas agressivas. Na América do Sul, encontrou-se respaldo em iniciativas menores, como a Estratégia Regional de Biodiversidade, dos países andinos, sem resultar, todavia, em iniciativas concretas. Na questão do controle das mudanças climáticas, por exemplo, o diálogo no continente é muito superficial. Nas questôes de acesso a recursos genéticos, não há nada além da ERB andina. No caso dos transgênicos, se não existe nem políticas nacionais claras, o que dizer das regionais? A Organização do Tratado de Cooperação Amazônica, infelizmente, também parece ter o mesmo destino do tratado que lhe deu origem, isto é, ficar no papel. Com relação aos regimes do mar e da pesca de uma maneira geral, pouco avanço foi observado na última década. Finalmente, no futuro regime de florestas, as negociações atuais não permitem augurar nenhum progresso significativo dentro do velho debate. Contudo, a fragilidade política e institucional instalada no continente de uma maneira geral, faz com que a grande parte dos temas sociais sejam paradoxalmente fortalecidos no discurso e fracassados na sua implementação.

É justamente esta incongruência, que não é apenas específica do nosso continente, mas também marca o mundo inteiro, o que contribui para a emergência das ONG's e demais atores da sociedade civil organizada como peças importantes do debate internacional. ${ }^{51}$ Assim, as comunidades científicas também foram fortalecidas pela mesma dinâmica,

51 ARTS, B. The Political Influence of Global NGOs: Case Studies on the Climate and Biodiversity Conventions, International Books, Utrecht, 1998, 351 p. Também os trabalhos de SYGNA, L.; ADGER, W. Rural Vulnerability to Global Change: the Role of Social Networks; AOKI INOUE, C. Global Regime for Biodiversity as an Approach to Study Local Level Experiencies. The Mamirauá Case; e NOMURA, K. Environmental Governance in Asia: blems aPrond Prospects - Opinion Survey of Major Environmental Actors, apresentados no "The 2003 Open Meeting on Human Dimensions of Global Environmental Change". Disponível em: http://sedac.ciesin. columbia.edu/openmeeting/. 
principalmente caso se parta de uma perspectiva de civilização do risco de Patrick Lagadec, ou sociedade do risco, como colocam Ulrich Beck, François Ost e Olivier Godard.

Em fato, as grandes ONG's internacionais (OING's) têm um papel cada vez mais importante no cenário internacional. Todavia, nota-se que muitas delas deixaram de exercer a função de oposição ao Estado e passaram a desempenhar outras, em parceria com ele, angariando um crescente reconhecimento institucional. ${ }^{52}$ Esta transição do "confronto à colaboração”, definida no Brasil por John Garrison, não é uma tendência linear e absoluta, mas crescente. É ponto pacífico que apenas protestar não garante mais a sobrevivência de nenhuma $\mathrm{ONG}$, as quais precisam participar mais ativamente das soluçôes para os problemas socioambientais, e com isso elas se profissionalizam gradativamente.

Se esta evolução foi vista como positiva por muitos analistas, outros alertam para o fato de o Estado delegar funções para atores do setor privado, ou ignorar suas obrigações para com os cidadãos, porque existem ONG's que estariam desempenhando tais funções, como a implantação e monitoramento de projetos. Além disso, há o risco de atores da sociedade civil organizada agirem por interesses próprios, e não em nome de um suposto interesse geral. Por exemplo, atores do mercado que realizam programas sociais têm normalmente interesses comerciais ou de imagem de marca por trás de suas ações, e a maioria dos Estados não consegue canalizar estas "forças emergentes" com vistas a uma verdadeira justiça distributiva. No caso das comunidades científicas, o grande desafio é o uso político do conhecimento gerado como fundamento para a ação política ou o seu adiamento. Em outros termos, a autoridade que os peritos ou cientistas detêm tende a ser reconhecida como justificativa política, mas eles são cidadãos e têm interesses específicos, sem terem, no entanto

\footnotetext{
52 Há muita literatura sobre esta tendência, mas vale a pena ler o Relatório do ex-presidente brasileiro Fernando Henrique Cardoso para a ONU "We the Peoples: Civil Society, the United Nations and Global Governance". Reporto f the Panel of Eminent Personson the United NationsCivil society Relations A/58/817 de 21 de junho de 2004. Disponível em www.un.org. Também KALDOR, M.; ANHEIER, H; GLASIUS, M. (eds.) Global Civil Society, Oxford: Oxford University Press, 2003, 434 p. E TIMMER, V. Promote, Protest, Partner: The Diverse Roles of Non-governmental Organizations in Addressing Global Environmental Change. Paper apresentado no "The 2003 Open Meeting on Human Dimensions of Global Environmental Change". Disponível em: http://sedac.ciesin.columbia.edu/openmeeting/.
} 
legitimidade para falar em nome do interesse geral da sociedade, pois não foram eleitos por ninguém. Assim, não é raro ver cientistas, como Veit Koester, negociando acordos ambientais em nome da sua delegação, como se ele fosse um diplomata. Em suma, a autoridade que lhes cabe na nossa sociedade da informação não foi delegada por ninguém, e o resto da sociedade civil tende a ser excluída do debate quando este se torna técnico e complexo demais.

\section{Novas dimensões do debate}

\section{Comércio e meio ambiente}

Após os anos noventa, uma nova dimensão jurídico-política emerge em alguns ramos do direito e da política internacional. Houve uma explosão de negociações e de normas com maiores graus de cogência, especialmente em se tratando de direitos internacional humanitário, econômico e ambiental. A legitimação e o aumento do número de ingerências humanitárias, com mais de mil resoluções aprovadas no Conselho de Segurança da ONU e centenas de outros atos desta natureza marcam o primeiro ponto. A criação da Organização Mundial do Comércio (OMC) e do conjunto normativo sob sua égide, com elevados níveis de cogência demonstra o segundo. A explosão de normas ambientais, com a realização de mais de dez grandes conferênciasquadro, nos anos 90 e início do novo século, mostram o crescimento da importância da questão ambiental.

No entanto, há um acúmulo de lógicas distintas, onde as diretrizes que guiam a questão ambiental são muitas vezes antagônicas àquelas que guiam as questões de ordem econômica. A oposição ou conjunção de interesses de diversos tratados multilaterais ambientais ao direito da OMC, neste sentido, é uma característica que limita ou potencializa a eficácia do direito internacional ambiental.

O direito internacional econômico é marcado por um conjunto de regras sob a égide de três grandes organizações internacionais com poder: o Banco Mundial, o Fundo Monetário Internacional e a Organização Mundial do Comércio. Trata-se de um sistema normativo, com uma lógica própria e autonomia perante os demais. Estas organizações não têm qualquer relação de dependência jurídica em relação à ONU. A 
OMC foi criada apenas em 1995 e traz um conjunto normativo extenso que pretende abranger a maioria dos temas ligados diretamente ou indiretamente ao comércio mundial. A eficácia do direito internacional econômico de caráter comercial está no Organismo de Solução de Controvérsias do OMC, que prevê sanções econômicas aos países que não cumprem com os acordos pré-estabelecidos. Neste sentido, o Organismo de Solução de Controvérsias condena os países-membro da OMC a alterarem suas normas internas - mesmo que seja sua constituição - sob pena de sanções econômicas. O nível de cumprimento das decisões da OMC é elevado, tendo em vista os impactos do descumprimento para os atores tanto do ponto de vista de perda de legitimidade de um instrumento internacional desejado, quanto da característica das sanções impostas.

O direito internacional ambiental, ao contrário do anterior, é marcado por um conjunto de tratados internacionais, criados no contexto de regimes diferentes, com diversificados níveis de cogência. Enquanto determinados temas evoluíram bastante em função dos interesses dos atores, como mudanças climáticas, proteção da camada de ozônio, restrições à pesca de baleias, outros não conseguem atingir níveis de compliance e enforcement suficientes para se tornarem eficazes, a exemplo do controle do acesso aos recursos genéticos e repartição de benefícios. O direito internacional ambiental está presente, sobretudo nas discussões realizadas no âmbito da ONU, mas também em diversos outros centros de realização de política e produção do direito internacional, como nas instituiçôes irmãs do direito internacional econômico ou em normas de caráter militar ou humanitário.

Por serem edificadas sobre lógicas distintas, diversas normas ambientais se contrapóem expressamente ao direito da Organização Mundial do Comércio. ${ }^{53}$ Entre os principais pontos de conflito percebe-se:

\footnotetext{
53 Sobre este assunto, consultar GONZALEZ-CALATAYUD, Alexandra \& MARCEAU, Gabrielle. "The relationship between the Dispute-Settlement Mechanisms of the MEA's and those of the WTO.” In RECIEL 11, 3, 2002, 275-286 p. Ou o artigo do professor da London School of Economics (LSE), Eric Neumayer em NEUMAYER, Eric. The WTO and the environment: it's past record is better than the critics believe but the future outlook is bleak. In: Global Environmental Politics 4, 3. Cambridge: MIT press, 2004.
} 
- A extraterritorialidade das medidas ou sua aplicação a Estados não-contratantes de acordos ou não-membros da OMC, permitida em certos acordos ambientais, mas proibidos pela OMC. As normas americanas para a proteção das tartarugas e dos golfinhos, com a promoção de restrições aos mecanismos de pesca de camaróes e de atum demonstraram o uso de normas, regulando a pesca em outros países, o que foi objeto de um painel na OMC, mas foi possível em função de tratados ambientais. ${ }^{54}$

- A designação de certos produtos não-comerciais ou a proibição de certos métodos de produção, permitida por certos acordos ambientais, mas proibido pela OMC. ${ }^{55}$ A Cites prevê, assim, condições estritas, regulamentando a exportação ou importação destas espécies, subordinando seu comércio a uma série de exigências que normalmente são contrárias à liberdade comercial. ${ }^{56} \mathrm{O}$ comércio destas espécies exige estudos de impacto, condiçóes especiais de transporte, parecer de técnicos e utilização do princípio da precaução. As partes são incitadas a tomar medidas de retaliação contra os Estados que não estão de acordo com as normas da convenção, como por exemplo, o confisco das espécies comercializadas. Nos últimos 15 anos, o Comitê da Cites recomendou de forma não obrigatória a suspensão do comércio com El Salvador, Itália, Grécia, Granada, Guiana, Senegal e Tailândia. Ele também determinou que controles rigorosos fossem feitos para as exportaçōes da Bolívia. ${ }^{57}$ O Protocolo de Montreal, sobre a proteção da camada de ozônio; a Convenção sobre a Proteção da Natureza e a Preservação da Vida Selvagem no Hemisfério Ocidental, de 1940; a Convenção

\footnotetext{
${ }^{54}$ Ver KACZKA, David. A primer on the shrimp-turtle controversy. In: RECIEL, 6, 2, 1997, 171-180 p.

${ }^{55}$ Ver Lei Geral n ${ }^{\circ}$ 101-162 (16 Código dos Estados Unidos (USC) parágrafo 1537, artigo 609. 56 Sobre a relação entre as regras da OMC e do arcabouço normativo disposto na Cites, favor consultar YEATER, Marceil \& VASQUEZ, Juan. Desmistifying the relationship between Cites and the WTO. In: RECIEL, 10, 3, 2001, 271-276 p.

${ }^{57} \mathrm{CTE}$. Dispositions des accords de l'OMCet des accords environnementaux multilatéraux relatives au respect des obligations et au règlement des différendsGenève, OMC, 2001, 7 p.
} 
sobre a Proteção dos Pássaros, de $1950 ;{ }^{58}$ o Acordo sobre os Ursos Polares, de 1973; a Convenção sobre a Conservação do Pacífico Norte e a e a Convenção sobre a Proteção das Peles de Focas, de 1976, também prevêem normas semelhantes.

- A diferenciação de produtos quimicamente equivalentes, em virtude do princípio da precaução, previsto por certos acordos ambientais, mas debatido no âmbito da OMC, como nas diferentes abordagens entre o protocolo de Cartagena, sobre organismos vivos modificados e os acordos sanitário e fitossanitários e de barreiras técnicas, ambos da OMC.

- A obrigação de cooperar antes da implementação de qualquer medida de sanção, obrigatória na $\mathrm{OMC}$, mas desnecessária em certos acordos ambientais, como a Cites.

- A escolha da entidade responsável para a solução de controvérsias, que nos tratados multilaterais ambientais podem variar desde instrumentos de solução arbitral, até a Corte Internacional de Justiça e na OMC são sempre em última instância o Órgão de Solução de Controvérsias.

Por se tratarem de conjuntos de normas autônomas, que não guardam relação de hierarquia entre si e não se submetem a lógica do direito doméstico, os instrumentos de solução de conflitos de normas não são operacionais para dizer qual o direito aplicável. O problema se agrava com o acúmulo de lógicas distintas entre os dois conjuntos normativos.

$\mathrm{Na}$ prática, a solução se dá com a maior eficácia no conjunto normativo mais forte, ou seja, aquele que aplica sançôes econômicas: a OMC. Neste sentido, os tratados multilaterais ambientais, quando em conflito com o direito da $\mathrm{OMC}$, dificilmente terão eficácia. No entanto, alguns outros tratados, pouco eficazes, podem ter sua eficácia catalisada pelo direito da OMC. O caso da positivação do princípio da precaução 59 é o exemplo mais marcante nos últimos anos: enquanto desconsiderado pela Corte Internacional de Justiça, no julgamento Gabcíkovo-Nagymaros, era reconhecido pela Organização Mundial do Comércio.

\footnotetext{
58 Atualmente, os objetos destas duas últimas convençôes são tratadas pela Cites, que prevê também sanções comerciais.

${ }^{59}$ Sobre o princípio da precaução ver: VARELLA, Marcelo Dias \& PLATIAU, Ana Flávia (Org.). O princípio da precaução. Belo Horizonte: Del Rey, 2004, 415 p.
} 


\section{Segurança e meio ambiente}

A passagem da sociedade moderna para aquela que Anthony Giddens e Ulrich Beck denominam "modernidade tardia", 60 trouxe consigo uma modificação social fundamental: uma profunda possibilidade de mudança na concepção de bem-estar. Tal modificação tem amplas implicaçōes para a relação entre meio ambiente e segurança, uma vez que possibilita uma transição entre a tradicional abordagem de "guerra por recursos" 61 para outra aqui definida como "segurança ambiental", ou seja, quando a relação entre homem e meio ambiente deixa de ser um problema de escassez e satisfação material, para tornar-se uma questão reflexiva ${ }^{62}$ sobre a vida e as condiçôes que a permitem. Em outras palavras, há uma grande transformação do espaço físico natural paralela à outra modificação profunda que diz respeito às identidades coletivas (soberania, sistema internacional, sociedade, sexualidade, etc.). Neste contexto de dupla transformação, ambiental e social, " [...] há algumas coisas dignas de serem seguradas; as dificuldades emergem da incerteza sobre o que estes objetos da segurança são no mundo pós-Guerra Fria, e quais meios justificam os fins". ${ }^{63}$ Portanto, quais são os "riscos" ambientais na sociedade pósmoderna? Quem é culpado? Enfim, quais são os objetos da segurança em um contexto de transformação ambiental global?

Em primeiro lugar, deve-se ter em mente que tanto para o meio ambiente, quanto para segurança a abordagem preponderante é a prevenção ou a precaução. Por precaução a Declaração do Rio (1992) determina que, em casos de danos ambientais irreversíveis, a falta de

60 Sobre este tema ver: GIDDENS, Anthony. As conseqüências da modernidade. São Paulo: UNESP, 1991; GIDDENS, Anthony. A transformação da intimidade: sexualidade, amor e erotismo nas sociedades modernas. São Paulo: UNESP, 1993; BECK, Ulrich. Risk society: towards a new modernity. London: Sage, 1992.

${ }^{61}$ Sobre a baixa correlação entre guerra e recursos naturais consultar ROSS, Michael. How do natural resources influence civil war? Evidence from thirteen cases. In: International Organization 58, Winter 2004, 35-67 p.

${ }^{62}$ A reflexividade da vida social moderna consiste no fato de que as práticas sociais são constantemente examinadas e reformadas a luz de informação renovada sobre estas próprias práticas, alterando assim constitutivamente seu caráter. Em: GIDDENS, Anthony. As conseqüências da modernidade. São Paulo: UNESP, 1991, 45 p.

${ }^{63}$ DYER, Hugh. Environmental security and international relations: the case for enclosure. In: Review of International Studies (2001), 27, 442 p. 
certeza científica não deve ser utilizada como razão para postergar medidas que previnam a degradação do meio ambiente. ${ }^{64} \mathrm{Ou}$ seja, o consagrado princípio da precaução dá a política e ao direito ambientais um caráter pró-ativo, onde o objeto da proteção passam a ser os riscos ambientais socialmente criados. ${ }^{65} \mathrm{Da}$ mesma forma as abordagens tradicionais de segurança internacional são calcadas na definição das potenciais ameaças - riscos - e elaboração de estratégias. Portanto, tanto a segurança quanto o meio ambiente estão apoiados na idéia de gestão de riscos e elaboração de respostas antecipadas, embora a primeira dê maior ênfase à idéia de prevenção - quando os riscos são conhecidos em detrimento da precaução - falta de certeza, científica ou não, sobre a existência de riscos.

Neste sentido duas questões estariam em ordem: quais as ameaças e riscos oriundos da degradação ambiental e por que as abordagens tradicionais de segurança são incapazes de incorporar questões relativas à transformação global do meio ambiente em seus cálculos? Com efeito, estas duas questôes estão intimamente interligadas a uma simples constatação: os problemas e os riscos ambientais são globais. Quem seria o culpado ou o "inimigo", por exemplo, nos casos do aquecimento global ou o buraco na camada de ozônio? A Terra? $\mathrm{O} \mathrm{CO}_{2}$ ? Os CFC's? As indústrias que produziram estes gases? Os países-sede destas empresas? O Direito Internacional Ambiental, por exemplo, tem trabalhado para consagração da responsabilidade civil em casos de dano ambiental, que pressupõe a exclusão do dolo e a obrigatoriedade da reparação. ${ }^{66} \mathrm{Ou}$ seja, cada vez mais se exclui a idéia do "culpado" no que concerne à crise ambiental global. Se há riscos, mas não há culpados, qual o papel reservado à segurança ambiental?

\footnotetext{
${ }^{64}$ De fato o Princípio da Precaução já é consagrado em inúmeros tratados ambientais como na Declaração do Rio (Princípio 15), Convenção-Quadro das Nações Unidas sobre Mudança do Clima (artigo 3[1]), Convenção da Biodiversidade (Preâmbulo), Protocolo de Cartagena sobre Biossegurança (preâmbulo), entre outros.

${ }^{65}$ Risk may be defined as a systematic way of dealing with hazards and insecurities induced and introduced by modernization itself. In: BECK, Ulrich. Risk society: towards a new modernity. London: Sage, 1992.

${ }^{66}$ Ver SOARES, Guido F. S. Direito internacional do meio ambiente: emergência, obrigaçôes e responsabilidades. São Paulo: Ed. Atlas, 2001.
} 
Primeiramente, deve ficar claro que por mais preventivas ou precaucionárias que sejam as ações no contexto dos riscos ambientais globais produzidos “[...] não á apenas o impacto da futura mudança ambiental global sobre os conflitos que necessita de atenção". ${ }^{67}$ De fato, além do impacto inverso, dos conflitos sobre o meio ambiente, Homer-Dixon \& Levy ressaltam que as questóes de escassez direcionam em maior grau a conflitos sub-regionais difusos e persistentes do que à guerra por recursos entre Estados. ${ }^{68}$ A partir desta figura não é estranho que haja carência de estudos e abordagens que privilegiem o global em favor do regional, uma vez que a primeira perspectiva leva necessariamente a uma baixa correlação entre guerra e recursos, conforme foi concluído anteriormente. Dois exemplos ilustrativos, que podem vir a ser duas das questóes mais problemáticas no contexto da redefinição da idéia de segurança ambiental, são os "refugiados ambientais" e o impacto da guerra no meio ambiente. Segundo o Alto Comissariado das Naçôes Unidas para Refugiados (Acnur), a questão de criação de novas classificações para determinadas migrações internacionais é central. ${ }^{69}$ No caso dos "refugiados ambientais" a migração poderia ocorrer tanto como resultado da degradação das regiōes de origem do migrante, quanto devido ao impacto deste último no meio ambiente do país alvo da migração. Em relação ao impacto da guerra no meio ambiente, episódios como a utilização o agente laranja durante a Guerra do Vietnam (o ano de introdução do agente da guerra foi exatamente em 1962) e a queima de poços de petróleo, durante a primeira Guerra do Iraque (1990) exemplificam a gravidade da questão.

A identidade mais provável para a segurança em nível global e preventivo gravitaria em torno da criação de condições para a gestão coletiva do meio ambiente, bem como a implementação das opções

${ }^{67}$ NOORDUYN, Ruth \& DE GROOT, Wouter. Environment and security: improving the interaction of the two science fields. In: Journal of Environment and Development 8, 1, 28 p. São Diego, março 1999.

68 Ver HOMER-DIXON, T. \& LEVY, M. Correspondence: environment and security. In: International Security 19, 1, 1995. Pg 189-198; HOMER-DIXON, T. Environmental scarcitites and violent conflict: evidence from cases. In: International Security 19, 1, 1994, 5-40 p; e LEVY, M. Is the environment a national security issue?. In: International Security 20, 2, 35-62 p. Cambridge: MIT press, 1995.

${ }^{69}$ Sobre a correlação entre migração e meio ambiente ver a edição especial da revista Refugiados do Acnur (n. $\left.{ }^{\circ} 115,2002\right)$. 
coletivamente aceitas, ou seja, trabalhar para a ampliação, efetividade e legitimidade da governança ambiental. Entre as opções neste nível analítico estariam a criação de planos emergenciais em contextos de crise - casos de vazamentos de resíduos tóxicos, químicos e radioativos, queimadas, enchentes; o auxílio na implementação de medidas sanitárias e fitosanitárias; a fiscalização em portos, estradas e aeroportos, com o objetivo de impedir o contrabando de animais e plantas, bem como o monitoramento de parques, reservas e outros locais de potencial acesso a recursos genéticos.

Para uma agenda de pesquisa mais objetiva, o conflito e a degradação ambiental aparecem como as duas variáveis centrais. Perguntas como: o que são os problemas ambientais e os de segurança?; quais são os atores envolvidos neste processo e como eles perdem ou ganham com mudanças específicas?; como elaborar soluçōes interdisciplinares? e, quais destes problemas e soluções podem ser antecipados?, são imperativas. Finalmente, é preciso que haja mais pesquisa empírica que correlacione as duas variáveis acima em níveis analíticos menores que o Estado, como o regional ou local.

\section{Conclusões}

Este artigo teve como objetivo analisar as opçóes e oportunidades que emergem para a governança ambiental a partir da definição de crise ambiental global. Em primeiro lugar, é necessário frisar que se por um lado a crise ambiental é de fato global, por outro a gestão coletiva, seja ela entendida pelas lentes de instituiçôes ou por arranjos mais flexíveis, não o é. A governança ambiental não é global. Ela transita entre o global e o local em um sistema internacional decadente. Como Lorraine Elliott nota “[...] há uma incongruência entre os problemas que se originam da natureza interconexa do ecossistema global e as soluções que são buscadas dentro do quadro de um sistema geopolítico baseado no Estado". ${ }^{70} \mathrm{Ou}$ seja, há uma incongruência entre "Terra, o conjunto das coisas físicas e naturais, e "Mundo, o conjunto das coisas sociais, políticas e econômicas."

\footnotetext{
${ }^{70}$ ELLIOTT, Lorraine. The global politics of the environment. New York: New York University Press, 1998, 97-98 p.
} 
Se a governança - em um "Mundo parcialmente globalizado - não é global, então qual o limiar que distingue o normativo do ontológico no diálogo entre relaçôes internacionais e o meio ambiente? Uma abordagem inicial poderia revelar que o problema é de fato deste campo do saber, uma vez que a ontologia e a epistemologia são interativas no sentido da "Hermenêutica Dupla” proposta por Anthony Giddens, ou melhor, "Como nós entendemos e interpretamos o mundo é parcialmente dependente de como nós definimos o mundo que nós estamos tentando entender e interpretar" ${ }^{71}$ Entretanto, a normatividade na discussão acerca da gestão coletiva do meio ambiente global parece estar melhor relacionada com o caráter global da crise ambiental, cuja resposta demandaria um processo de gestão inclusivo, tanto na tomada de decisão, quanto na implementação. Assim, a governança global seria muito normativa no sentido proposto por Rosenau \& Czempiel e positiva em demasia na proposta de Keohane. A governança ambiental precisa de um conceito que seja o ponto médio entre as duas propostas anteriores e inclua o caráter fragmentário e excludente do globalismo "econômico".

Com relação ao papel dos atores, é de bom alvitre ressaltar a crise ambiental que se está gerando, além da grande crise institucional que abarca outros campos, e principalmente o da segurança coletiva. Desta feita, o discurso do multilateralismo, da reforma do sistema ONU e da governança global revelam alto grau de normatividade e baixo grau em termos de operacionalidade, engendrando uma forte decepção por parte da sociedade civil organizada. A partir deste contexto, e da evolução do cenário internacional, que permitiu a maior participação e atores não-estatais, como as ONG's e as comunidades científicas nos processos decisórios, nota-se o reconhecimento institucional de "forças emergentes" capazes de trazer renovado impulso à governança ambiental, do nível global ao local. No entanto, a irrupção de atores tão assimétricos e diversos também traz novos desafios no estabelecimento das regras do jogo internacional, que sempre foram pouco claras para as questôes ambientais.

$\mathrm{Na}$ questão da interface entre o regime comercial da OMC e os regimes ambientais, é preciso enfatizar que mesmo tendo sido

71 BROWN, Chris. Understanding International Relations. 2 ed. New York: Palgrave, 2001, 1-2 p. 
construídos com lógicas distintas e sem uma hierarquia no direito internacional, o primeiro tende a prevalecer, por ter mostrado, em menos de dez anos de existência, que a regulação comercial por meios multilaterais institucionalizados é desejável. A clareza (precisão) das normas estabelecidas, e a sua observância, bem como o nível de delegação por parte dos membros são suficientemente assegurados para que o regime seja forte, o que não ocorre na maioria dos regimes internacionais ambientais. Porém, não obstante tantas diferenças, não se pode concluir que são necessariamente regimes contraditórios, uma vez que algumas decisões da OMC privilegiaram a dimensão ambiental de maneira surpreendente.

Por fim, é imperativa a reformulação do papel da segurança no contexto da crise ambiental global. O meio ambiente não deve ser entendido apenas como um conjunto de recursos que devem ser protegidos para assegurar o bem estar do homem. Ao contrário, uma nova abordagem para a segurança deve garantir a vida, a participação e a legitimidade, não exclusivamente a satisfação pessoal por intermédio do consumo descontrolado, pois como lembra Karl Marx, o capitalismo é uma via irracional para dirigir o mundo moderno, porque ele substitui a satisfação controlada das necessidades humanas pelos caprichos do mercado.

Outubro de 2004

\section{Resumo}

O artigo tem como objetivo analisar as opções e oportunidades que emergem para a governança ambiental a partir da definição de crise ambiental global. Para tal, faz-se um exame detalhado dos três grupos em torno dos quais a teoria das relações internacionais tem analisado o processo de gestão coletiva da referida crise, bem como a eficácia das respostas institucionais já existentes. Finalmente, o artigo faz uma releitura das questões de comércio e meio ambiente e segurança ambiental.

\section{Abstract}

This article aims to analyze the options and opportunities available to environmental governance, starting from a definition of the global environmental crisis. The article provides a detailed analysis of the three clusters 
under which the international relations theory has investigated the collective management of this environmental crisis as well as the effectiveness of current institutional answers. Finally, the article reexamines matters pertaining to trade and environment and to environmental security.

Palavras-Chave: Organizações Internacionais; Regimes Internacionais; Governança; Meio Ambiente.

Keywords: International organizations; international regimes; governance; environment. 